\title{
Report on the Annual Meeting of the Working Group "Phytobacteriology"
}

The Working Group Phytobacteriology of the German Society of Plant Protection and Plant Health (DPG) met on September 30 - October 1, 2010 at Jena University. The well organised meeting was hosted by Dr. Beate Völksch and her team. Eighteen lectures covered applied as well as fundamental aspects of phytobacteriology and the approx. 40 participants received a good overview on recent phytobacteriological research projects. Typical disease symptoms, detection protocols and monitoring results were presented for a number of pathogens, such as Acidovorax valerianellae, Clavibacter michiganensis ssp. michiganensis., Erwinia chrysanthemi/Dickeya spp. or Xanthomonas arboricola pv. pruni. Methods applicable for differentiation between very closely related bacteria such as the subspecies of Pantoea stewartii or isolates of E. amylovora of varying geographical origin were described. Development of host plant defense was presented in a study on phytoalexin development in apple following fire-blight infection. Adaptation mechanisms of bacteria to the plant environment were also investigated for pathogenic bacteria and potential antagonists. Two presentations focused on the impact of HexR regulator on pathogenic $P$. syringae. Another study demonstrated genetic differences between pathogenic and epiphytic isolates of $P$. syringae pv. syringae. Which parameters make an epiphyte a potential antagonist were discussed on examples like $P$. syringae, $P$. agglomerans, E. tasmaniensis and isolates of the Serratia/Rhanella group. In addition to the abstracts published here the abstracts of the presentations are hosted on the homepage of the DPG (www.phytomedizin.org/ phytobakteriologie.html).

At the end of the meeting the working group leaders were elected for the next four-year term. Dr. Esther Moltmann will be the head with Dr. Annette Wensing as the deputy. The next meeting will be at the Center for Agricultural Technology in Karlsruhe on September 1-2, 2011.

Dr. Esther Moltmann (Landwirtschaftliches Technologiezentrum Augustenberg, Stuttgart) and Dr. Annette Wensing (JKI, Institut für Pflanzenschutz im Obst- und Weinbau, Dossenheim)

\section{Naturally occuring nonpathogenic strains of Pseudomonas syringae}

\section{Völksch, Beate}

Friedrich-Schiller-Universität Jena, Institut für Mikrobiologie, Mikrobielle Phytopathologie, Neugasse 25, D-07743 Jena

Pseudomonas syringae is best known as a plant pathogen that infects hundreds of plant species and cause disease symptoms ranging from leaf spots to blights and cankers. P. syringae contains a hypersensitive response and pathogenicity (hrp)-genesencoded type III secretion system (T3SS) to deliver effector proteins into plant cells, which both restrict and promote specific pathogen-host interactions. It was reported recently, that a small phylogenetic subgroup of $P$. syringae strains exists, which does not induce HR and does not cause disease on any tested plant species. It was assumed that these $P$. syringae strains have an entirely non-pathogenic life style. $P$. syringae Pss22d is an interesting biocontrol strain against bacterial blight of soybeans caused by $P$. syringae pv. glycinea. The strain was isolated from a symptomless soybean leaf. Pss22d also belongs to the newly described phylogenetic subgroup 2c based on multilocus sequence analysis of four housekeeping genes. P. syringae group 2c strains and Pss22d also contain an unusual hrp/hrc cluster that is only distantly related to the canonical $P$. syringae hrp/hrc cluster. The main difference is the lack of hrpK (effector translocation) and hrpS genes (response regulator) at the $P$. syringae $2 \mathrm{c}$ group. Nonetheless, group 2c $P$. syringae strains reach in planta population densities as well as or higher than pathogenic $P$. syringae strains on nonhost plants without causing symptoms. In addition, these strains do not cause HR when high doses are injected into tobacco leaves. The encoded T3SS appears to be constitutively expressed and functional but has no apparent role during in planta growth. Perhaps, the non-pathogenic nature of these $P$. syringae - being a generalist - could be advantage for their distribution and the completion of their life cycle.

\section{Phytoalexin formation in fire blight-infected Malus domestica cv. Holsteiner Cox}

Hüttner, C. ${ }^{1}$, Beuerle, T. ${ }^{1}$, Liu, B. ${ }^{1}$, Richter, K. ${ }^{2}$, Flachowsky, H. ${ }^{3}$, Peil, A. ${ }^{3}$, Hanke, M.-V. ${ }^{3}$, Beerhues, L. ${ }^{1}$

1 Institute of Pharmaceutical Biology, Braunschweig

2 Institute for Resistance Research and Stress Tolerance, Quedlinburg

3 Institute for Breeding Research on Horticultural and Fruit Crops, Dresden

In response to fire blight the accumulation of biphenyls and structurally related dibenzofurans was detected in the Malus domestica cultivar Holsteiner Cox. The formation of these compounds as phytoalexins was reported for a number of Pyrinae species and appears to be unique to this Rosaceous subtribe. Biphenyl synthase (BIS) is the key enzyme catalysing the condensation of benzoyl-CoA with three molecules of malonyl-CoA to give 3,5-dihydroxybiphenyl (Liu et al. 2007). This product serves as a biosynthetic precursor of a variety of biphenyl and dibenzofuran phytoalexins (Hüttner et al. 2010). Three isoforms of BIS were cloned from elicitor-treated $M$. domestica cell cultures. After inoculation of intact plants of M. domestica cv. Holsteiner Cox with the fire blight bacterium Erwinia amylovora, a number of biphenyl and dibenzofuran phytoalexins were detected in the stem's transition zone after the infection had stopped. High expression of the BIS 3 gene was observed in upper stem parts starting from the second day after inoculation, whereas no BIS 1 and BIS 2 transcripts were induced. Leaves of $E$. amylovora-infected plants were devoid of biphenyls or dibenzofurans and the expression levels of the three BIS genes were significantly lower than in the stems. A bactericidal effect of 3,5-dihydroxybiphenyl was shown with in vitro inhibition assays (ED $50: 90 \mu \mathrm{M}$ ). Immunofluorescence localisation of BIS is under work to gain deeper insight into the spatial regulation of biphenyl and dibenzofuran biosynthesis as an important defense pathway. Transgenic apple lines either expressing polyketide synthases related to BIS or containing promoter-GUS constructs have been generated and are being analysed.

References

Liu B, Raeth T, Beuerle T \& Beerhues L, 2007. Biphenyl synthase, a novel type III polyketide synthase. Planta 225, 1495-1503.

Hüttner et al., 2010. J. Agric. Food Chem., in press. 